\title{
Application of morphometric analysis to patients with lung cancer metastasis to the spine: a clinical study
}

\author{
Hesham Mostafa Zakaria, MD, ${ }^{1}$ Azam Basheer, MD, ${ }^{1}$ David Boyce-Fappiano, BS, ${ }^{2}$ \\ Erinma Elibe, BS, ${ }^{2}$ Lonni Schultz, PhD, ${ }^{3}$ Ian Lee, MD, ${ }^{1}$ Farzan Siddiqui, MD, PhD, ${ }^{2}$ \\ Brent Griffith, MD, ${ }^{4}$ and Victor Chang, MD ${ }^{1}$
}

Departments of ${ }^{1}$ Neurosurgery, ${ }^{2}$ Radiation Oncology, ${ }^{3}$ Public Health Sciences, and ${ }^{4}$ Radiology, Neuroscience Institute, Henry Ford Health System, Detroit, Michigan

\begin{abstract}
OBJECTIVE Predicting the survival rate for patients with cancer is currently performed using the TNM Classification of Malignant Tumors (TNM). Identifying accurate prognostic markers of survival would allow better treatment stratification between more aggressive treatment strategies or palliation. This is especially relevant for patients with spinal metastases, who all have identical TNM staging and whose surgical decision-making is potentially complex. Analytical morphometrics quantifies patient frailty by measuring lean muscle mass and can predict risk for postoperative morbidity after lumbar spine surgery. This study evaluates whether morphometrics can be predictive of survival in patients with spinal metastases.
\end{abstract}

METHODS Utilizing a retrospective registry of patients with spinal metastases who had undergone stereotactic body radiation therapy, the authors identified patients with primary lung cancer. Morphometric measurements were taken of the psoas muscle using CT of the lumbar spine. Additional morphometrics were taken of the L-4 vertebral body. Patients were stratified into tertiles based on psoas muscle area. The primary outcome measure was overall survival, which was measured from the date of the patient's CT scan to date of death.

RESULTS A total of 168 patients were identified, with $54 \%$ male and $54 \%$ having multiple-level metastases. The median survival for all patients was 185.5 days (95\% confidence interval [Cl] 146-228 days). Survival was not associated with age, sex, or the number of levels of metastasis. Patients in the smallest tertile for the left psoas area had significantly shorter survival compared with a combination of the other two tertiles: 139 days versus 222 days, respectively, hazard ratio $(\mathrm{HR}) 1.47,95 \% \mathrm{Cl} 1.06-2.04, p=0.007$. Total psoas tertiles were not predictive of mortality, but patients whose total psoas size was below the median size had significantly shorter survival compared with those greater than the median size: 146 days versus 253.5 days, respectively, $\mathrm{HR} 1.43,95 \% \mathrm{Cl} 1.05-1.94, p=0.025$. To try to differentiate small body habitus from frailty, the ratio of psoas muscle area to vertebral body area was calculated. Total psoas size became predictive of mortality when normalized to vertebral body ratio, with patients in the lowest tertile having significantly shorter survival $(p=0.017)$. Left psoas to vertebral body ratio was also predictive of mortality in patients within the lowest tertile $(p=0.021)$. Right psoas size was not predictive of mortality in any calculations.

CONCLUSIONS In patients with lung cancer metastases to the spine, morphometric analysis of psoas muscle and vertebral body size can be used to identify patients who are at risk for shorter survival. This information should be used to select patients who are appropriate candidates for surgery and for the tailoring of oncological treatment regimens. http://thejns.org/doi/abs/10.3171/2016.5.FOCUS16152

KEY WORDS morphometrics; lung cancer mortality; Stage IV lung cancer; spine complications; frailty index; spinal metastases; spine surgery; morphometric analysis; oncologic outcomes

$\mathrm{P}$ ATIENT frailty has been defined as a decreased reserve and resistance to stressors, with decline across multiple physiological systems, and is a common end point in human senescence. ${ }^{12,43}$ For a surgeon, the clinical appreciation of a frail patient is important, as a recent body of literature has shown that frailty can predict morbidity and mortality after general, vascular, transplant, and neurological surgery. ${ }^{6,17,28,33,56,57}$ Unfortunately, measuring human frailty is subjective, burdensome, and impractical in most clinical settings. ${ }^{2,33,57}$ Therefore, surrogate mark-

ABBREVIATIONS $\mathrm{Cl}=$ confidence interval; $\mathrm{HR}=$ hazard ratio; $\mathrm{TNM}=\mathrm{TNM}$ Classification of Malignant Tumors.

SUBMITTED April 1, 2016. ACCEPTED May 26, 2016.

INCLUDE WHEN CITING DOI: 10.3171/2016.5.FOCUS16152. 
ers of frailty, namely sarcopenia, have been successfully used to predict postoperative morbidity and mortality following major surgery, $, 10,17,28,40,46,56$ including lumbar spine surgery. ${ }^{57}$ Morphometrics is the measurement of patient attributes that are indicative of sarcopenia and, by extension, frailty.

In terms of oncological surgery, the observation has consistently been that patients who are sarcopenic not only have increased rates of postoperative morbidity and mortality, but also have shorter progression-free survival. ${ }^{19,23,37,46}$ The relationship between increased muscle mass and disease-free survival has even been observed in oncological patients who have not undergone any cancer surgery. ${ }^{13,16,24,38,44,50,55}$ This is a notable observation, as current methodologies for predicting oncological outcomes rely solely on histological grade of the malignancy and its TNM Classification of Malignant Tumors (TNM). Identifying more accurate and specific markers of survival would enable oncologists to discern which patients are appropriate candidates for a particular treatment, be it chemotherapy, radiation, surgery, or palliation.

In this study, we applied morphometric analysis of psoas muscle size to predict oncological outcomes in patients who have had lung cancer metastases to the spine. In our previous work, we identified patients who were at higher risk of postoperative morbidity after lumbar spine surgery by using the psoas area as a marker for sarcopenia. ${ }^{57}$ Our hypothesis is that patients with lung cancer metastasis to the spine will have shorter survival if they have less lean muscle mass as measured by the psoas area.

\section{Methods \\ Data Acquisition}

This study was approved by the Henry Ford Hospital Institutional Review Board. Using a retrospective registry of patients with spinal metastases from 2002 to 2012 who had undergone stereotactic body radiation therapy, we reviewed and identified a population of patients diagnosed with primary lung cancer. This review included all histological subtypes of lung cancer. Additional treatments such as radiation therapy or chemotherapy were inconsistently documented and therefore not included in data acquisition. It should be noted, however, that most patients with lung cancer would have received radiation therapy to the primary site with some form of chemotherapy.

\section{Morphometric Analysis}

The full extent of our methodology for morphometric analysis has been described previously ${ }^{57}$ Briefly, morphometric measurements were taken of the psoas muscle at the L-4 level, and a Philips ePACS viewer was used to measure the circumference (in $\mathrm{cm}^{2}$ ) of each patient's psoas muscles. In addition, the L-4 vertebral body area was measured and recorded in similar fashion. Measurements were made using the patient's most recent CT scan of the lumbar area. Psoas muscle sizes were divided into tertiles according to total psoas area. Because the psoas measurements were dependent on sex, the tertiles for left, right, and total psoas were computed within the male and female cohorts separately using different cutoff points. In addition, the ratio of left, right, and total psoas area to the vertebral body area was considered. Tertiles were computed for these new variables using different cutoff points for males and females. Besides the tertile cutoff points, the median cutoff point was also investigated.

In addition to absolute psoas size, we also attempted to normalize psoas size based on each individual patient's stature. Intuitively, patients with smaller stature will tend to have smaller psoas sizes. As a result, these patients would not necessarily be sarcopenic nor at risk for shorter survival. Our method of normalization of psoas muscle size with body habitus consisted of calculating the ratio of psoas muscle area to vertebral body area as a separate variable for morphometric analysis. The primary outcome measure was overall survival, which was measured from the date of the patient's scan to date of death. For patients who were still alive at the time of analysis, survival was calculated to the most recent documented follow-up evaluation.

\section{Statistical Analysis}

The median survival in days along with the corresponding 95\% confidence interval (CI) was computed for all patients, as well as subsets of interest. Cox proportional hazards regression analyses were done to estimate the hazard ratios (HRs) and test for differences in the variables of interest. All testing was done at the 0.05 level. The statistical program SAS (version 9.4, SAS Institute) was used for data analysis.

\section{Results}

There were 168 patients with spinal metastases from lung cancer identified and included in this study. There was 1 person without a right and total psoas measurement because of the location of the tumor. Patient demographics can be found in Table 1. The average age ( \pm SD) at the time of CT scan was $65.3 \pm 11.3$ years, with a range from 33 to 97 years old. Ninety (54\%) of the patients were male. There were 78 patients $(46 \%)$ with single-level metastases and 90 (54\%) with multiple-level metastases. There were 24 patients (14.3\%) treated surgically in this series, with 6 (3.6\%) undergoing instrumentation.

The median survival for all patients was 185.5 days (95\% CI 146-228 days). The associations of overall survival with age, sex, and the number of levels were not significant (Table 2). Comparisons of psoas size with survival can be found in Table 3. When considering the total and mean psoas tertiles, no significant differences in survival were detected. However, the difference between patients above and below the median of total psoas size and the median of mean psoas size was significant, with patients below the median having shorter survival (HR 1.43, p = 0.025 for total psoas size; HR 1.42, $\mathrm{p}=0.026$ for mean psoas size). The Kaplan-Meier survival curves for this data set provide a visual representation of the differences in survival between these two groups (Fig. 1). Using the left psoas only, patients in the lowest tertile (smallest psoas size) had significantly shorter survival (median 139 days) as compared with the middle (median 164 days, $p=0.038$ ) and highest (median 263 days, $p=0.011$ ) tertiles. Survival 
TABLE 1. Patient demographics

\begin{tabular}{cc}
\hline \multicolumn{1}{c}{ Variable } & Value \\
\hline Age (yrs) & $65.3(11.3)$ \\
\hline Mean (SD) & $64(33-97)$ \\
\hline Median (range) & $90(54)$ \\
\hline Sex (\%) & $78(46)$ \\
\hline Male & \\
\hline Female & $104(62)$ \\
\hline Race (\%) & $52(31)$ \\
\hline Caucasian & $7(4)$ \\
\hline African American & $5(3)$ \\
\hline Other & \\
\hline Not available & $78(46)$ \\
\hline No. of levels treated (\%) & $55(33)$ \\
\hline 1 & $23(14)$ \\
\hline 2 & $9(5)$ \\
\hline 3 & $2(1)$ \\
\hline 4 & $1(0.6)$ \\
\hline 5 & $51.7(39.3)$ \\
\hline 6 & $41.3(0.565-209)$ \\
\hline Target volume in ml (\%)*
\end{tabular}

* In 143 patients.

of the lowest tertile was also significantly decreased when compared with a combination of the other two tertiles, 139 days versus 222 days, respectively $(\mathrm{p}=0.007)$. The Kaplan-Meier survival curve for morphometrics based on left psoas size is shown in Fig. 2. No significant differences were detected for the right psoas, using both tertile and median cutoff points.

We also performed a similar analysis using values for psoas size that were normalized for patient size by calculating a ratio of psoas muscle area to vertebral body area (Table 4). When applying this ratio to total psoas size, patients in the lowest tertile had statistically significant shorter survival as compared with the combination of the other two tertiles (HR 1.49, 95\% CI 1.07-2.07, p = $0.017)$. This normalization increased the sensitivity of our morphometric analysis, as total psoas size tertiles without normalization to vertebral body size did not show any statistically significant differences in survival (Table 2). The Kaplan-Meier survival curves of total psoas size to vertebral body ratio are shown in Fig. 3. Similar results were found for the ratio of left psoas size to vertebral body size, as patients in the lowest tertile had significantly shorter survival than a combination of the other two tertiles (HR $1.47,95 \%$ CI 1.06-2.04, $\mathrm{p}=0.021$ ). No significant differences were detected for the ratio of right psoas size to vertebral body size.

\section{Discussion}

Since the publication of Patchell et al.'s seminal study on surgical treatment of patients with spinal metasta-
TABLE 2. Overall survival and patient demographics

\begin{tabular}{lcccc}
\hline \multicolumn{1}{c}{ Variable } & $N$ & $\begin{array}{c}\text { Median Days of } \\
\text { Survival }(95 \% \mathrm{Cl})\end{array}$ & HR $(95 \% \mathrm{Cl})$ & $\mathrm{p} \mathrm{Value}$ \\
\hline Age & & (Increase over 10 yrs) & $0.92(0.79-1.06)$ & 0.234 \\
\hline Sex & & & & \\
\hline Male & 90 & $188.5(138-273)$ & Reference & 0.505 \\
\hline Female & 78 & $179.5(124-222)$ & $1.11(0.81-1.52)$ & \\
\hline No. of levels & & & \\
\hline Single & 78 & $183(132-254)$ & Reference & 0.412 \\
\hline Multiple & 90 & $185.5(133-230)$ & $1.14(0.84-1.55)$ & \\
\hline
\end{tabular}

ses, ${ }^{39}$ there has been an interest in spinal oncology as a subspecialty and subsequently a growing body of literature regarding outcomes on the subject. ${ }^{4,5,20,27,42}$ Surgical decision-making for this population can be challenging. While surgery can improve overall survival and neurological outcome, and provide pain control, these procedures delay cancer treatments (chemotherapy and radiation) and are resource intensive. , $14,18,21,22,51$ Surgical risk is also high, with postoperative morbidity as high as $76 \%, 7$ which may diminish any benefit of surgery and hasten patient demise.

Several authors have reported different classification schemes attached to surgical decision-making algorithms to treat the patient with spinal metastasis in general. ${ }^{11,26 \text {, }}$ ${ }_{45,52,53}$ However, these scoring systems have a limited prognostic capability. ${ }^{14,41,49}$ With continued refinements to surgical technique as well as advances in implant technology, surgeons are able to undertake increasingly ambitious resections followed by complex reconstructions. ${ }^{1,25,35} \mathrm{An}$ objective assessment of fitness for surgery would provide insight into which patients are better surgical candidates. There is a recently established and objective scoring system designed specifically to predict functional outcome and survival in surgical patients with lung cancer metastases to the spine; ${ }^{29-32}$ this system uses markers of disease severity (visceral metastases, multiple-level metastases, inability to ambulate, etc.) to predict surgical outcome and survival. Our work differs in several ways. Our work identifies at-risk patients independent of the extent of metastases and in a nonsurgical population, and so it may be applicable in a broader sense. Psoas size, as a surrogate for frailty, has been verified to be predictive of morbidity and mortality after both general $l^{9,10,17,28,40,46,56}$ and spine surgery. ${ }^{57}$ While our current results did not focus on morbidity and mortality after oncological surgery, we did show that patients who were sarcopenic, as measured by a morphometric analysis of psoas size, had decreased survival. This morphometric parameter can be applied in conjunction with other classification criteria to help guide surgical decision-making. An observation of small psoas size and risk of shorter survival could be useful in determining if a patient is unfit for surgery.

The use of the vertebral body measurement to successfully normalize body habitus has been performed in trauma patients, ${ }^{8}$ as well as in the assessment of peripheral vascular disease ${ }^{48}$ with mixed results. Its current application - to predict mortality in oncological patients-is novel. The impetus for finding a way to normalize each 
TABLE 3. Overall survival and psoas size*

\begin{tabular}{|c|c|c|c|c|}
\hline Variable & $\mathrm{N}$ & Median Days of Survival $(95 \% \mathrm{Cl})$ & $\mathrm{HR}(95 \% \mathrm{Cl})$ & $p$ Value \\
\hline \multicolumn{5}{|l|}{ Total psoas tertiles } \\
\hline Lowest & 55 & $157(107-204)$ & $1.38(0.94-2.02)$ & 0.10 (1 vs 3) \\
\hline Middle & 57 & $133(102-230)$ & $1.28(0.87-1.88)$ & 0.202 (2 vs 3 ) \\
\hline Highest & 55 & $280(191-356)$ & $1.07(0.74-1.57)$ & 0.71 (1 vs 2) \\
\hline \multicolumn{5}{|l|}{ Mean psoas tertiles } \\
\hline Lowest & 57 & $173(115-204)$ & $1.34(0.92-1.95)$ & 0.124 (1 vs 3) \\
\hline Middle & 53 & $127(101-237)$ & $1.21(0.83-1.79)$ & 0.323 (2 vs 3 ) \\
\hline Highest & 58 & $270.5(191-337)$ & $1.10(0.75-1.62)$ & 0.613 (1 vs 2 ) \\
\hline \multicolumn{5}{|l|}{ Total psoas } \\
\hline Less than median & 84 & $146(115-186)$ & $1.43(1.05-1.94)$ & 0.025 \\
\hline Greater than median & 83 & $253.5(179-302)$ & Reference & \\
\hline \multicolumn{5}{|l|}{ Mean psoas } \\
\hline Less than median & 83 & $146(115-186)$ & $1.42(1.04-1.94)$ & 0.026 \\
\hline Greater than median & 85 & $253(174-302)$ & Reference & \\
\hline \multicolumn{5}{|l|}{ Lt psoas tertiles } \\
\hline Lowest & 55 & $139(91-185)$ & $1.65(1.12-2.42)$ & 0.011 (1 vs 3) \\
\hline Middle & 57 & $164(115-269)$ & $1.10(0.75-1.61)$ & 0.636 (2 vs 3 ) \\
\hline Highest & 56 & 263 (191-337) & $1.50(1.02-2.20)$ & $\mathbf{0 . 0 3 8}$ (1 vs 2) \\
\hline \multicolumn{5}{|l|}{ Lt psoas $†$} \\
\hline Lowest & 55 & $139(91-185)$ & $1.57(1.13-2.20)$ & 0.007 \\
\hline Middle \& highest & 113 & $222(164-288)$ & Reference & \\
\hline \multicolumn{5}{|l|}{ Rt psoas tertiles } \\
\hline Lowest & 55 & $173(115-214)$ & $1.39(0.95-2.03)$ & 0.094 (1 vs 3 ) \\
\hline Middle & 56 & $136(102-211)$ & $1.29(0.88-1.90)$ & 0.187 (2 vs 3 ) \\
\hline Highest & 56 & $276(191-337)$ & $1.07(0.73-1.53)$ & 0.723 (1 vs 2 ) \\
\hline
\end{tabular}

patient comes from the observation that patients who have a small body habitus may not be sarcopenic, and would be falsely classified as more frail by measuring lean muscle mass alone without normalization. The vertebral body, in a nonpathological state, maintains its size independent of age. ${ }^{34}$ Because the origin of the psoas muscle size is on the

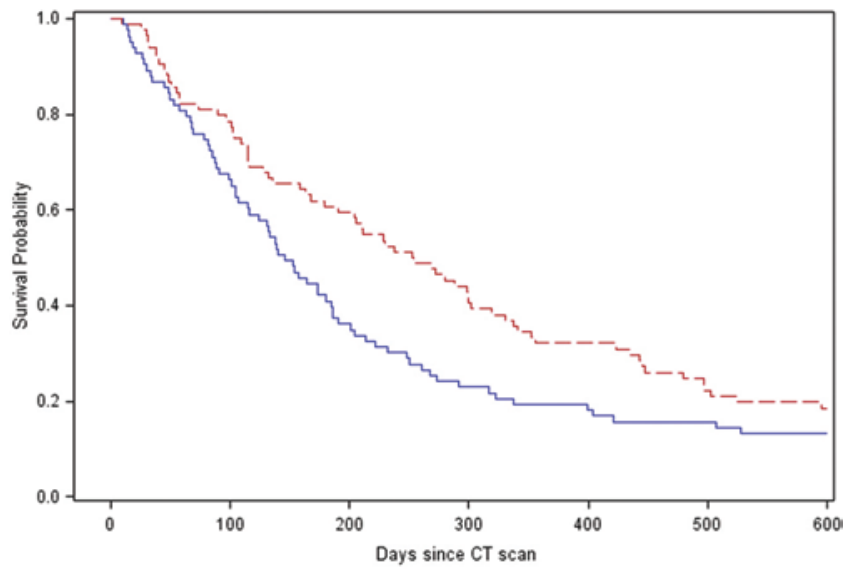

Total Psoas median cutpoint —- Below --- Above

FIG. 1. Kaplan-Meier survival curve of total psoas size using median as the cutoff point. transverse process of the spine, it is intuitive that a normal psoas muscle size should be in proportion to the size of the vertebral body. Calculating a ratio between psoas size and vertebral body size could provide a more accurate measurement of sarcopenia.

It is important to note that we observed a statistically significant relationship with survival when looking at total

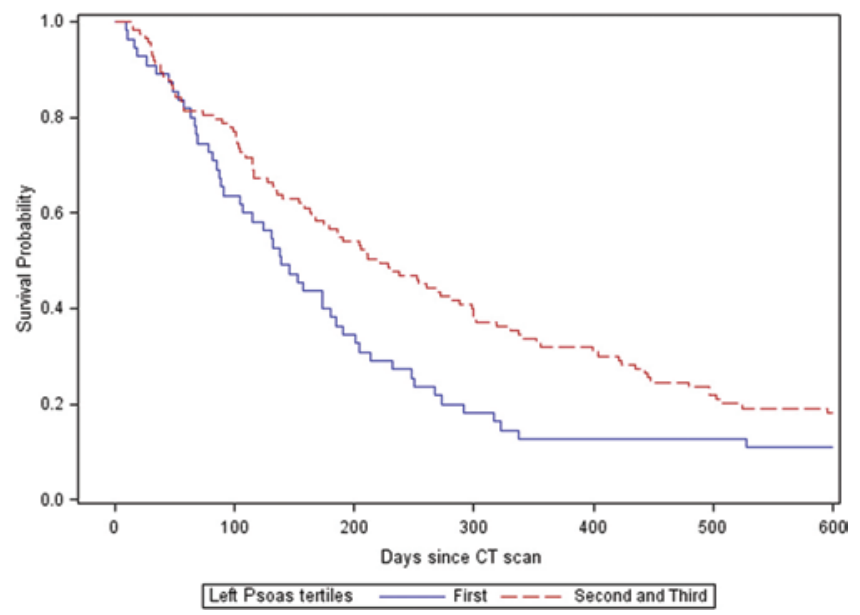

FIG. 2. Kaplan-Meier survival curve of left psoas tertiles. 
TABLE 4. Comparison of overall survival and psoas size to vertebral body ratio*

\begin{tabular}{|c|c|c|c|c|}
\hline Variable & $\mathrm{N}$ & Median Days of Survival $(95 \% \mathrm{Cl})$ & $\mathrm{HR}(95 \% \mathrm{Cl})$ & $p$ Value \\
\hline \multicolumn{5}{|c|}{ Ratio of total psoas to vertebral body area† } \\
\hline Lowest tertile & 56 & $138.5(83-191)$ & $1.49(1.07-2.07)$ & 0.017 \\
\hline Middle \& highest tertile & 111 & $211(168-288)$ & Reference & \\
\hline \multicolumn{5}{|c|}{ Ratio of It psoas to vertebral body area† } \\
\hline Lowest tertile & 56 & $135(85-168)$ & $1.47(1.06-2.04)$ & 0.021 \\
\hline Middle \& highest & 112 & $216.5(179-280)$ & Reference & \\
\hline \multicolumn{5}{|c|}{ Ratio of rt psoas to vertebral body area } \\
\hline Lowest tertile & 57 & $153(99-214)$ & $1.14(0.78-1.67)$ & 0.489 (1 vs 3$)$ \\
\hline Middle tertile & 53 & $191(133-288)$ & $1.05(0.72-1.54)$ & 0.798 (2 vs 3 ) \\
\hline Highest tertile & 57 & $228(124-302)$ & $1.09(0.74-1.68)$ & 0.665 (1 vs 2) \\
\hline
\end{tabular}

psoas size, mean psoas size, and left psoas size, but not for the right psoas. These results were maintained even after internal normalization with vertebral body size. On closer analysis of our previous results predicting morbidity after lumbar spine surgery, ${ }^{57}$ we also found that the right psoas size did not provide statistical significance, but total psoas size, mean psoas size, and left psoas size did. In coordination, these two findings suggest that this observation may be a reflection of reality, whereas the left psoas muscle may be a better indicator of sarcopenia or frailty. To our knowledge, this is the first time that this phenomenon has been identified in the psoas size morphometric literature. We are unable to identify a plausible rationale at this moment, although we hypothesize that left cerebral hemispheric dominance causes attenuation of right-sided sarcopenia due to the more frequent use of that side. Ultimately, further and more comprehensive studies are required to explore this finding to definitively conclude whether this observation is a true reflection of the general population.

Our study illustrates that morphometric analysis of psoas size is predictive of survival in patients with lung cancer metastasis to the spine. These findings have potential applications to oncology as well as neurosurgery. Lung

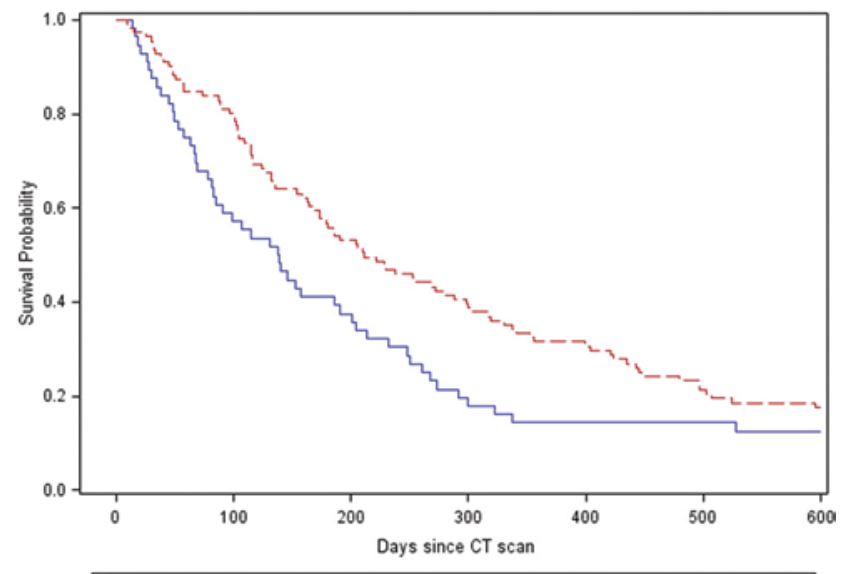

Ratio total psoas to vertebral body area tertiles __ First - - Second and Third

FIG. 3. Kaplan-Meier survival curve of total psoas to vertebral body ratio tertiles. cancer is common and the leading cause of cancer death in the world. ${ }^{54}$ The 5-year survival rate for patients with lung cancer is poor-only $17 \%$ of patients in all stages of the disease-with only a $2 \% 5$-year survival rate for patients with Stage IV cancer. ${ }^{15}$ All patients in our cohort had Stage IV lung cancer, given that all had distant metastases to the spine ${ }^{36}$ From an oncological perspective, there are treatments available at this stage of lung cancer, but current guidelines recommend basing treatment strategies on a patient's performance status. ${ }^{47}$ To date there are no studies that directly compare performance status with frailty. However, it has been reported that frail patients may have poor performance status, but a poor performance status does not always indicate frailty. ${ }^{12,43}$ Our results suggest that analytical morphometrics as a measurement of frailty can be predictive of survival in patients with lung cancer. The ultimate utility of this finding, which can only be achieved after further testing and validation, would be to use psoas size to guide oncological treatment by identifying those patients who are better suited for aggressive interventions.

The chief limitation of our study is its retrospective nature. While the electronic medical record is robust, we are unable to account for any hidden bias associated with retrospective studies. Prospective multicenter studies would be necessary to further validate our findings.

\section{Conclusions}

Morphometric analysis of psoas size can be used to predict survival in patients with lung cancer metastases to the spine. With further work and validation, this information could be used to select patients who are appropriate candidates for surgery and for the tailoring of oncological treatment regimens. Further research is needed to confirm these results and to see if these methodologies can be applied to other cancer histologies.

\section{References}

1. Ames CP, Wang VY, Deviren V, Vrionis FD: Posterior transpedicular corpectomy and reconstruction of the axial vertebra for metastatic tumor. J Neurosurg Spine 10:111-116, 2009

2. Amrock LG, Deiner S: The implication of frailty on preoper- 
ative risk assessment. Curr Opin Anaesthesiol 27:330-335, 2014

3. Bollen L, de Ruiter GC, Pondaag W, Arts MP, Fiocco M, Hazen TJ, et al: Risk factors for survival of 106 surgically treated patients with symptomatic spinal epidural metastases. Eur Spine J 22:1408-1416, 2013

4. Choi D, Crockard A, Bunger C, Harms J, Kawahara N, Mazel $\mathrm{C}$, et al: Review of metastatic spine tumour classification and indications for surgery: the consensus statement of the Global Spine Tumour Study Group. Eur Spine J 19:215-222, 2010

5. Choi D, Fox Z, Albert T, Arts M, Balabaud L, Bunger C, et al: Rapid improvements in pain and quality of life are sustained after surgery for spinal metastases in a large prospective cohort. Br J Neurosurg 30:337-344, 2016

6. Cloney M, D'Amico R, Lebovic J, Nazarian M, Zacharia BE, Sisti MB, et al: Frailty in geriatric glioblastoma patients: a predictor of operative morbidity and outcome. World Neurosurg 89:362-367, 2016

7. Dea N, Versteeg A, Fisher C, Kelly A, Hartig D, Boyd M, et al: Adverse events in emergency oncological spine surgery: a prospective analysis. J Neurosurg Spine 21:698-703, 2014

8. Ebbeling L, Grabo DJ, Shashaty M, Dua R, Sonnad SS, Sims $\mathrm{CA}$, et al: Psoas:lumbar vertebra index: central sarcopenia independently predicts morbidity in elderly trauma patients. Eur J Trauma Emerg Surg 40:57-65, 2014

9. Englesbe MJ, Lee JS, He K, Fan L, Schaubel DE, Sheetz KH, et al: Analytic morphomics, core muscle size, and surgical outcomes. Ann Surg 256:255-261, 2012

10. Englesbe MJ, Patel SP, He K, Lynch RJ, Schaubel DE, Harbaugh C, et al: Sarcopenia and mortality after liver transplantation. J Am Coll Surg 211:271-278, 2010

11. Fourney DR, Frangou EM, Ryken TC, Dipaola CP, Shaffrey CI, Berven SH, et al: Spinal instability neoplastic score: an analysis of reliability and validity from the spine oncology study group. J Clin Oncol 29:3072-3077, 2011

12. Fried LP, Tangen CM, Walston J, Newman AB, Hirsch C, Gottdiener J, et al: Frailty in older adults: evidence for a phenotype. J Gerontol A Biol Sci Med Sci 56:M146-M156, 2001

13. Fujiwara N, Nakagawa H, Kudo Y, Tateishi R, Taguri M, Watadani T, et al: Sarcopenia, intramuscular fat deposition, and visceral adiposity independently predict the outcomes of hepatocellular carcinoma. J Hepatol 63:131-140, 2015

14. Ghori AK, Leonard DA, Schoenfeld AJ, Saadat E, Scott N, Ferrone ML, et al: Modeling 1-year survival after surgery on the metastatic spine. Spine J 15:2345-2350, 2015

15. Gloeckler Ries LA, Reichman ME, Lewis DR, Hankey BF, Edwards BK: Cancer survival and incidence from the Surveillance, Epidemiology, and End Results (SEER) program. Oncologist 8:541-552, 2003

16. Harada K, Ida S, Baba Y, Ishimoto T, Kosumi K, Tokunaga $\mathrm{R}$, et al: Prognostic and clinical impact of sarcopenia in esophageal squamous cell carcinoma. Dis Esophagus [epub ahead of print], 2015

17. Hasselager R, Gögenur I: Core muscle size assessed by perioperative abdominal CT scan is related to mortality, postoperative complications, and hospitalization after major abdominal surgery: a systematic review. Langenbecks Arch Surg 399:287-295, 2014

18. Holman PJ, Suki D, McCutcheon I, Wolinsky JP, Rhines LD, Gokaslan ZL: Surgical management of metastatic disease of the lumbar spine: experience with 139 patients. J Neurosurg Spine 2:550-563, 2005

19. Itoh S, Shirabe K, Matsumoto Y, Yoshiya S, Muto J, Harimoto N, et al: Effect of body composition on outcomes after hepatic resection for hepatocellular carcinoma. Ann Surg Oncol 21:3063-3068, 2014

20. Janssen SJ, Teunis T, van Dijk E, Ferrone ML, Shin JH, Hornicek F, et al: Validation of the Spine Oncology Study
Group-Outcomes Questionnaire to assess quality of life in patients with metastatic spine disease. Spine J [epub ahead of print], 2015

21. Kim CH, Chung CK, Jahng TA, Kim HJ: Resumption of ambulatory status after surgery for nonambulatory patients with epidural spinal metastasis. Spine J 11:1015-1023, 2011

22. Kim JM, Losina E, Bono CM, Schoenfeld AJ, Collins JE, Katz JN, et al: Clinical outcome of metastatic spinal cord compression treated with surgical excision \pm radiation versus radiation therapy alone: a systematic review of literature. Spine (Phila Pa 1976) 37:78-84, 2012

23. Kuroki LM, Mangano M, Allsworth JE, Menias CO, Massad LS, Powell MA, et al: Pre-operative assessment of muscle mass to predict surgical complications and prognosis in patients with endometrial cancer. Ann Surg Oncol 22:972979, 2015

24. Lanic H, Kraut-Tauzia J, Modzelewski R, Clatot F, Mareschal S, Picquenot JM, et al: Sarcopenia is an independent prognostic factor in elderly patients with diffuse large B-cell lymphoma treated with immunochemotherapy. Leuk Lymphoma 55:817-823, 2014

25. Lau D, Chou D: Posterior thoracic corpectomy with cage reconstruction for metastatic spinal tumors: comparing the mini-open approach to the open approach. J Neurosurg Spine 23:217-227, 2015

26. Laufer I, Rubin DG, Lis E, Cox BW, Stubblefield MD, Yamada Y, et al: The NOMS framework: approach to the treatment of spinal metastatic tumors. Oncologist 18:744-751, 2013

27. Lee BH, Park JO, Kim HS, Park YC, Lee HM, Moon SH: Perioperative complication and surgical outcome in patients with spine metastases: retrospective 200-case series in a single institute. Clin Neurol Neurosurg 122:80-86, 2014

28. Lee JS, He K, Harbaugh CM, Schaubel DE, Sonnenday CJ, Wang SC, et al: Frailty, core muscle size, and mortality in patients undergoing open abdominal aortic aneurysm repair. J Vasc Surg 53:912-917, 2011

29. Lei M, Li J, Liu Y, Jiang W, Liu S, Zhou S: Who are the best candidates for decompressive surgery and spine stabilization in patients with metastatic spinal cord compression (MSCC)? A new scoring system. Spine (Phila Pa 1976) [epub ahead of print], 2016

30. Lei M, Liu Y, Liu S, Wang L, Zhou S, Zhou J: Individual strategy for lung cancer patients with metastatic spinal cord compression. Eur J Surg Oncol 42:728-734, 2016

31. Lei M, Liu Y, Tang C, Yang S, Liu S, Zhou S: Prediction of survival prognosis after surgery in patients with symptomatic metastatic spinal cord compression from non-small cell lung cancer. BMC Cancer 15:853, 2015

32. Lei M, Liu Y, Yan L, Tang C, Yang S, Liu S: A validated preoperative score predicting survival and functional outcome in lung cancer patients operated with posterior decompression and stabilization for metastatic spinal cord compression. Eur Spine J [epub ahead of print], 2015

33. Makary MA, Segev DL, Pronovost PJ, Syin D, BandeenRoche K, Patel P, et al: Frailty as a predictor of surgical outcomes in older patients. J Am Coll Surg 210:901-908, 2010

34. Masharawi Y, Salame K, Mirovsky Y, Peleg S, Dar G, Steinberg N, et al: Vertebral body shape variation in the thoracic and lumbar spine: characterization of its asymmetry and wedging. Clin Anat 21:46-54, 2008

35. Miller DJ, Lang FF, Walsh GL, Abi-Said D, Wildrick DM, Gokaslan ZL: Coaxial double-lumen methylmethacrylate reconstruction in the anterior cervical and upper thoracic spine after tumor resection. J Neurosurg 92 (2 Suppl):181-190, 2000

36. Mirsadraee S, Oswal D, Alizadeh Y, Caulo A, van Beek E Jr: The 7th lung cancer TNM classification and staging system: Review of the changes and implications. World J Radiol 4:128-134, 2012 
37. Miyamoto Y, Baba Y, Sakamoto Y, Ohuchi M, Tokunaga R, Kurashige $\mathrm{J}$, et al: Sarcopenia is a negative prognostic factor after curative resection of colorectal cancer. Ann Surg Oncol 22:2663-2668, 2015

38. Parsons HA, Baracos VE, Dhillon N, Hong DS, Kurzrock $\mathrm{R}$ : Body composition, symptoms, and survival in advanced cancer patients referred to a phase I service. PLoS One 7:e29330, 2012

39. Patchell RA, Tibbs PA, Regine WF, Payne R, Saris S, Kryscio RJ, et al: Direct decompressive surgical resection in the treatment of spinal cord compression caused by metastatic cancer: a randomised trial. Lancet 366:643-648, 2005

40. Peng P, Hyder O, Firoozmand A, Kneuertz P, Schulick RD, Huang D, et al: Impact of sarcopenia on outcomes following resection of pancreatic adenocarcinoma. J Gastrointest Surg 16:1478-1486, 2012

41. Quraishi NA, Manoharan SR, Arealis G, Khurana A, Elsayed $\mathrm{S}$, Edwards KL, et al: Accuracy of the revised Tokuhashi score in predicting survival in patients with metastatic spinal cord compression (MSCC). Eur Spine J 22 (Suppl 1):S21S26, 2013

42. Quraishi NA, Rajabian A, Spencer A, Arealis G, Mehdian H, Boszczyk BM, et al: Reoperation rates in the surgical treatment of spinal metastases. Spine J 15 (3 Suppl):S37-S43, 2015

43. Ruiz M, Cefalu C, Reske T: Frailty syndrome in geriatric medicine. Am J Med Sci 344:395-398, 2012

44. Sabel MS, Lee J, Cai S, Englesbe MJ, Holcombe S, Wang S: Sarcopenia as a prognostic factor among patients with stage III melanoma. Ann Surg Oncol 18:3579-3585, 2011

45. Schoenfeld AJ, Le HV, Marjoua Y, Leonard DA, Belmont PJ Jr, Bono CM, et al: Assessing the utility of a clinical prediction score regarding 30-day morbidity and mortality following metastatic spinal surgery: the New England Spinal Metastasis Score (NESMS). Spine J 16:482-490, 2016

46. Sheetz KH, Zhao L, Holcombe SA, Wang SC, Reddy RM, Lin J, et al: Decreased core muscle size is associated with worse patient survival following esophagectomy for cancer. Dis Esophagus 26:716-722, 2013

47. Socinski MA, Evans T, Gettinger S, Hensing TA, Sequist LV, Ireland B, et al: Treatment of stage IV non-small cell lung cancer: Diagnosis and management of lung cancer, 3rd ed: American College of Chest Physicians evidence-based clinical practice guidelines. Chest 143 (5 Suppl):e341S-e368S, 2013

48. Swanson S, Patterson RB: The correlation between the psoas muscle/vertebral body ratio and the severity of peripheral artery disease. Ann Vasc Surg 29:520-525, 2015

49. Tabouret E, Cauvin C, Fuentes S, Esterni B, Adetchessi T, Salem N, et al: Reassessment of scoring systems and prognostic factors for metastatic spinal cord compression. Spine J 15:944-950, 2015

50. Tan BH, Birdsell LA, Martin L, Baracos VE, Fearon KC: Sarcopenia in an overweight or obese patient is an adverse prognostic factor in pancreatic cancer. Clin Cancer Res 15:6973-6979, 2009
51. Tatsui CE, Suki D, Rao G, Kim SS, Salaskar A, Hatiboglu MA, et al: Factors affecting survival in 267 consecutive patients undergoing surgery for spinal metastasis from renal cell carcinoma. J Neurosurg Spine 20:108-116, 2014

52. Tokuhashi Y, Matsuzaki H, Oda H, Oshima M, Ryu J: A revised scoring system for preoperative evaluation of metastatic spine tumor prognosis. Spine (Phila Pa 1976) 30:2186-2191, 2005

53. Tomita K, Kawahara N, Kobayashi T, Yoshida A, Murakami $\mathrm{H}$, Akamaru T: Surgical strategy for spinal metastases. Spine (Phila Pa 1976) 26:298-306, 2001

54. Torre LA, Bray F, Siegel RL, Ferlay J, Lortet-Tieulent J, Jemal A: Global cancer statistics, 2012. CA Cancer J Clin 65:87-108, 2015

55. Villaseñor A, Ballard-Barbash R, Baumgartner K, Baumgartner R, Bernstein L, McTiernan A, et al: Prevalence and prognostic effect of sarcopenia in breast cancer survivors: the HEAL Study. J Cancer Surviv 6:398-406, 2012

56. Waits SA, Kim EK, Terjimanian MN, Tishberg LM, Harbaugh CM, Sheetz KH, et al: Morphometric age and mortality after liver transplant. JAMA Surg 149:335-340, 2014

57. Zakaria HM, Schultz L, Mossa-Basha F, Griffith B, Chang $\mathrm{V}$ : Morphometrics as a predictor of perioperative morbidity after lumbar spine surgery. Neurosurg Focus 39(4):E5, 2015

\section{Disclosures}

Dr. Lee has consulting agreements with Medtronic and Monteris, and has received honoraria and travel expenses from Varian Medical Systems. Dr. Siddiqui has received clinical or research support from Varian Medical Systems for the study described, honoraria from MD Anderson SBRT Symposium, St. John Providence Hospital, the American College of Veterinary Radiology, and Wayne State University, and has received medical grants from Philips Medical. Dr. Chang has consulting agreements with DePuy Synthes and Globus, and has received clinical or research support from Medtronic for the study described.

\section{Author Contributions}

Conception and design: Zakaria, Chang, Lee, Siddiqui. Acquisition of data: Zakaria, Chang, Basheer, Boyce-Fappiano, Elibe. Analysis and interpretation of data: Chang, Zakaria, Schultz, Lee. Drafting the article: Zakaria, Chang, Schultz. Critically revising the article: Chang, Zakaria, Basheer, Lee, Siddiqui. Reviewed submitted version of manuscript: all authors. Approved the final version of the manuscript on behalf of all authors: Chang. Statistical analysis: Schultz. Study supervision: Chang.

\section{Correspondence}

Victor Chang, Department of Neurosurgery, Henry Ford West Bloomfield Hospital, 6777 W Maple Blvd., West Bloomfield Township, MI 48322. email: vchang1@hfhs.org. 